This investigation has been made at the request of Prof. A1bert B. Prescott, to whom I wish to express my thanks for counsel in the work.

UNIVERSity OF Michigan, April 25, I8g9.

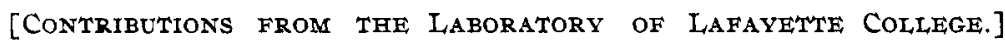

\title{
A SIMPLIFIED REDUCTOR.
}

BY P. W. SHIMER.

Received June 3,1899 .

$G$ OR the reduction of iron and phosphomolybdate solutions, I $F$ have been using, for some time, a form of reductor which is simple, convenient, and effective. The reductor tube is a plain glass tube three-eighth inch in internal diameter and twenty inches long, drawn-out and cut off at the lower end. It is filled by placing a few small pieces of broken glass in the drawn-out portion and on this about an inch of well-cleaned sand. The tube is then filled with amalgamated zinc of as nearly uniform twenty mesh size as possible. About eighty grams are required. No asbestos or glass wool is used. The sand prevents particles of zinc from falling through, and it does not become clogged by use. Should any error arise on account of the omission of a more perfect filter, it would show in the blank, which is, however, uniformly very small, not more than 0.05 to $0.10 \mathrm{cc}$. permanganate.

The use of amalgamated zinc, as proposed by A. G. McKenna, makes a small reductor possible. The consumption of zinc is very small, and when the column has settled about one inch, a little fresh zinc can easily be poured in above. The reductor tube is united with a four-inch funnel by means of rubber tubing, well tightened with wire. Between the funnel and reductor is a Hoffman clamp. The lower end of the tube passes through a soft two-hole stopper so far as to reach half way to the bottom of a heavy-walled pint gas-bottle. The gas-bottle is connected with a filter-pump through an intermediate safety-bottle and valve. The funnel is clamped to a retort stand in such a 
manner as to allow the tube and gas-bottle to swing easily in all directions. It is well to so adjust the height as to leave the gasbottle raised slightly above the base. The passage of the solution through the reductor may be effected either by use of the pump, or by means of the vacuum obtained by condensation of steam, devised originally in Bunsen's laboratory. In using the latter method a little water may be boiled in the gas-bottle until all air is expelled and then quickly unite with the reductor, the clamp on the filter-pump tube being closed. The speed of filtration is regulated by the upper clamp. Instead of filling the gas-bottle with steam by boiling water in it, it is better to have a convenient tin or copper can containing boiling water and frovided with one or more short steam outlet tubes on top. The empty gas-bottle is inverted over one of these steam outlets and, when filled with live steam, is taken off and united as quickly as possible with the reductor. This latter method has the advantage of starting with an empty gas-bottle, which is desirable, on the score of accuracy, both in iron and phosphorus determinations. When a large number of reductions have to be made, a number of reductors may be used, and, with a steam vessel provided with a number of outlets, gasbottles may always be ready for reductions.

The hot lower part of the reductor in the gas-bottle is particularly effective in perfecting the reduction of phosphomolybdate solutions. The reduction is to $\mathrm{Mo}_{24} \mathrm{O}_{57}$ and the factor is 0.88163 .

A few phosphorus determinations are the following:

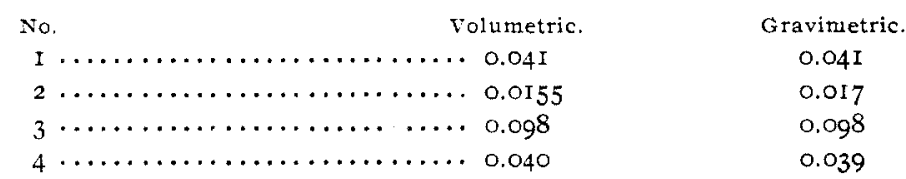

A few iron determinations in Alabama red ore are as follows: $48.52,48.52,48.5 \mathrm{I}, 48.46,48.52$.

By reduction with five grams zinc in a flask the result on this ore was 48.45 .

The speed of filtration through the reductor should not be too rapid. From three and a half to five minutes should be allowed for a reduction. 